\title{
Validation of Academic Delay of Gratification Scale among Indian Professional Courses Students
}

\author{
Rajib Chakraborty ${ }^{1 *}$
}

\section{ABSTRACT}

The present study is an attempt to conduct factor analysis of the Academic Delay of Gratification Scale (ADOGS) for college students, with 10 items, prepared by Bembenutty and Karabenick (1998), on Indian professional courses students. 461 students (256 boys and 205 girls) from engineering, pharmacy, law and education professional courses of Sultan Ul Uloom Education Society, Hyderabad, voluntarily participated in the study, out of which 336 students (190 boys and 146 girls) were part of exploratory factor analysis. With the help of SPSS Statistics Ver.23, Principal Axis Factor extraction method and Varimax rotation, two factors were extracted. Monte Carlo PCA Parallel Analysis was used to settle for one factor explaining 16\% variance. The reliability of the instrument using Cronbach's Alpha was found to be 0.715 . SPSS Amos Ver. 23 was used to confirm the factor structure and establish within-network construct validity of the instrument using Fit index tests like Chi test $\mathrm{p}$ value, DF, CMIN/DF, TLI, CFI, IFI, NFI,RMR and RMSEA from the data of 125 students (66 boys and 59 girls), followed by between network validity based on construct validation approach using Pearson's product moment correlation the data of 136 students (100 boys and 36 girls) measuring their academic delay of gratification and emotional intelligence. There were sufficient evidences to establish that this instrument in its present form can be administered on Indian urban students for the measurement of academic delay of gratification.

Keywords: Academic Delay of Gratification Scale, Academic Delay of Gratification, Factor Analysis, Exploratory Factor Analysis, Confirmatory Factor Analysis

Students pursuing professional courses invest significant amount of time and efforts before realizing their dreams. They are supposed to exhibit "willingness to forgo an immediately available option, in favor of a delayed alternative, in order to secure temporarily distant academic rewards, goals, and intentions” (Bembenutty, 1998).

\footnotetext{
${ }^{1}$ Asst. Professor, Ghulam Ahmed College of Education, Banjara Hills, Osmania University, Telangana, India *Responding Author

Received: February 7, 2017; Revision Received: February 21, 2017; Accepted: February 28, 2017 (C) 2017 Chakraborty R; licensee IJIP. This is an Open Access Research distributed under the terms of the Creative Commons Attribution License (www.creativecommons.org/licenses/by/2.0), which permits unrestricted use, distribution, and reproduction in any Medium, provided the original work is properly cited.
} 
This ability is operationally defined as Academic Delay of Gratification and its presence in a university student is related to academic success, intrinsic motivation, self efficacy and use of cognitive, meta-cognitive and resource management strategies in studies (Bembenutty, 1998). Even in school students, it is an important component for the promotion of self regulated learning and leads to several desirable outcomes in education (Zhang,. L., Karabenick, S. A., \& Lauermann, F. ,2011).

Such an important construct is measured using a 10 item scale for college students prepared by Hefer Bembenutty and Stuart A. Karabenick (Bembenutty,.H. \& Karabenick,S.A.,1998). The tool was originally developed in the United States with the American students as sample. Before the tool is administered on students from non-western country like India, its validation through factor analysis is necessary to establish relevance (Markus \& Kitaynama, 1991, King and Du, 2011) and hence this study.

\section{LITERATURE REVIEW}

A detailed review of the literature of academic delay of gratification construct and its role in initiating the present study was carried out by the researcher in the previous study (Chakraborty, .R. 2016).

\section{METHODOLOGY}

\section{The Study}

A construct validation can be classified as either between-network or within network in type. Within-network construct validation involves factor structure examination using the statistical techniques like exploratory factor analysis, confirmatory factor analysis and reliability analysis of a construct. It is also called as internal construct validation.

In between network construct validity or external construct validation approach, the relationship of the construct with other theoretically related constructs is examined using correlation or regression statistical techniques (March, 1997). In this study, both the approaches are used to establish the validity of academic delay of gratification scale.

First, as part of within-network validation approach exploratory factor analysis is carried out to extract the single factor of ADOG and measure the internal consistency reliability of the instrument when administered on the sample of the study using Cronbach's alpha.

Then, confirmatory factor analysis is carried out to confirm the single factor structure and measure the strength and nature of the correlation between academic delay of gratification and emotional intelligence using Pearson’s Product Moment correlation statistical technique. 
The researcher in his previous study (Chakraborty,. R., \& Prabhakaram, K.S.,2015), proposed that the neural grid between amygdala, prefrontal fortex and ventral striatum can be responsible from the standpoint of Neuroscience for relation between academic delay of gratification and emotional intelligence. This association was found to be positive in nature and weak in strength but significant in secondary school students. The study is repeated on professional courses university students for gaining between-network construct validity evidence of academic delay of gratification. The trait emotional intelligence of the professional courses college students was measured using the Trait Emotional Intelligence Questionnaire - Adolescent Short Form (TEIQue-ASF,2006), which is a simplified version of The Trait Emotional Intelligence Questionnaire - Short Form (TEIQUE-SF, Petrides and Furnham, 2004), which consist of 30 items and responses spread across a seven point Likert scale.

\section{Participants}

461 students (256 boys and 205 girls) from engineering, pharmacy, law and education professional courses of Sultan Ul Uloom Education Society, Telangana, Hyderabad, voluntarily participated in the study, out of which 336 students (190 boys and 146 girls) were part of exploratory factor analysis, and data of 125 students (66 boys and 59 girls) was used for confirmatory factor analysis for within-network construct validity study. The data of 136 students was used in correlation study for between-network construct validity study. All the

students received instructions in English throughout their academic life and were fluent in the language.

\section{Instruments}

\section{Measuring Academic Delay of Gratification}

The Academic Delay of Gratification scale has 10 items. The scale was prepared based on three criteria. Firstly, every item presented two alternatives to the students, one which provided immediate reward and the other delayed reward. Secondly, both the alternatives resulted in specific outcomes in studies. While the alternative involving the delayed reward increased the possibility of academic success, the other alternative involving instant gratification decreased such a possibility. Thirdly, from the student's point of view, selection of the more delayed reward alternative was more valuable.

The items covered several academic experiences like "meeting deadlines on assignments, use of the library, interpersonal relations with peers and instructors, and studying course materials". The students responded in a four point Likert-type scale for items like "Go to a favorite concert, play or sporting event and study less for this course even though it may mean getting a lower grade on an exam you will take tomorrow, or Stay home and study to increase your chances of getting a higher grade".

The four responses are "Definitely choose A", "Probably choose A, Probably choose B, Definitely choose B”. The responses are coded from 1 to 4 and the mean score, obtained by dividing the total score by 10 provides the measure of academic delay of gratification. The 


\section{Validation of Academic Delay of Gratification Scale among Indian Professional Courses Students}

higher is the mean score between 1 and 4, the greater is the presence of the trait in the subject.

Factor analysis of the scale during its development revealed two factors from principal component analysis with varimax rotation and Keiser criterion of root one. While items 1, 3,4,5,6,8, presenting choices between academic and non-social alternative activities, loaded on factor 1, items 2,7,9, and 10, presenting choices between academic and social alternatives, loaded on factor 2 . Both the factors together explained $47 \%$ of variance in the construct. However, the Cronbach's alpha of the tool was obtained as 0.77 which above the generally accepted value of 0.7 for internally consistency. Hence, the use of subscales or the idea of multidimensionality of the construct was dropped and the scale measured only academic delay of gratification from the total score (Bembenutty,.H. \& Karabenick,S.A.,1998).

\section{Measuring Emotional Intelligence}

The Trait Emotional Intelligence Questionnaire - Adolescent Short Form (TEIQue ASF, 2006), was used to measure the emotional intelligence in adolescent college students. It was derived from the originally prepared instrument by Petrides, K. V., Sangareau, Y., Furnham, A., \& Frederickson, N. (2006), to measure emotional intelligence in adults. The instrument contains 30 items, two from each of the 15 trait EI facets like self esteem, empathy, social awareness, relationships, which measure global trait EI. The subjects provide the responses on a seven point Likert-type scale, ranging from strongly disagree 1 to strongly agree 7 . The internal consistency of the original tool was reported to be above 0.80 .

The items with positive responses are forward coded and the rest are reverse coded. The mean score can range between 1 and 7 and higher the score greater the presence of trait in the individual.

\section{Statistical Analysis}

During exploratory factor analysis, the data was not normally distributed as KomolgorovSmirmov test and Shapiro Wilk's test produced significant results. Hence Principal axis factoring method of extraction was chosen to find the factor structure (Fabrigar et.al., 1999). Parallel analysis is an accurate method to decide the factors to be retained (Velicer and Jackson, 1990). It was used with the help of Monte Carlo PCA Parallel Analysis software. The most common choice of Varimax rotation was selected in this study. The subject to item ratio for determining the sample size was chosen to be 20:1 for getting correct factor structure (Costello and Osberne, 2005). For minimum loading of an item on a factor, the thumb rule of 0.32 was considered (Tabachnick and Fidell, 2001) and a factor with less than three items loading on it was considered weak and the one with five or more was considered strong.

In Confirmatory factor analysis, a good model fit would provide an insignificant result of Chisquare value at a 0.05 threshold (Barrett, 2007). Df and p value must be reported always and 
hence included (Kline, 2004 \& Hayduk et al, 2007). Chi-square can be significant for a large sample test and show poor fit even though the reality is otherwise, as this test is sensitive to sample size (Gerbing and Anderson,1985). That is why, CMIN/DF is reported which should not be more than 3 for a reasonably good fit (Kline, 2004). Among SEM fit indices, Chi-square is the only inferential statistics. Other goodness of fit tests are RMR, GFI. IFI, TLI, RMSEA CFI. While RMR and RMSEA values are recommended to be below 0.08 , the rest of the values are recommended to be above 0.93 (Leech et.al, 2008). These descriptive statistics have only rulesof-thumbs or cut-off values (Iacobucci,.D., 2009) and are used here for providing within-network validity evidence. For providing evidence of between-network validity, the correlation of academic delay of gratification and emotional intelligence is considered. G power software was used for statistical power analysis to determine the sample size for level of significance 0.05 , effect size 0.3 (medium) and power 0.9. The software provided the minimum sample size to be 112. A sample size of 136 was actually used in the study. SPSS version 23 provided the nature and strength of the correlation between EI and ADOG using Pearson product moment correlation method. The same software was used for determining the internal consistency measure Cronbach's alpha of the instrument recommended to be above 0.7 for a uni-dimensional set of sample items (Nunnally and Bernstein 1994, Bland and Altman, 1997 \& DeVellis, 2003). Cronbach alpha was measured for both EFA and CFA as conducted on fresh samples. It is because " alpha is a property of the scores on a test from a specific sample of testees", the researcher should not rely on the published alpha estimates and must measure alpha every time the test is administered on a new sample (Streiner, 2003).

\section{RESULTS}

The Cronbach's alpha of academic delay of gratification scale was found to be 0.715 for a sample size of 336 professional courses students in this study, which is well above the cut-off value of 0.7. It means that the scale is found to be reliable. Exploratory factor analysis, using principal axis factoring extraction method and varimax rotation produced a factor which eigen value 1.619 which is greater than the randomly generated eigen value 1.2751, by Monte Carlo PCA parallel analysis software for 100 iterations. The other eigen value of the second factor extracted was 0.908 less than the second random eigen value 1.1906 of parallel analysis. So, the researcher settled with one factor extraction for academic delay of gratification.

Second sample consisting of 125 students with Cronbach's alpha 0.742 was used for confirmatory factor analysis. Except item 4 (factor loading 0.17) all the items had strong factor loading on ADOG construct (as shown in table table 1), well above the cut-off value of 0.32, fig.1.

The chi-test was non-significant with $\mathrm{p}$ value at 0.319 for $\mathrm{df} 35$. The CMIN/DF value was 1.097 (less than the cut-off value of 3). The RMR value at 0.069 and the RMSEA value at 0.028 were less than the cut-off value of 0.08 . The GFI value was 0.944 . The IFI value was 0.981 . 
Validation of Academic Delay of Gratification Scale among Indian Professional Courses Students

Table 1. Items-Factor Loading - ADOGS

\begin{tabular}{|c|c|}
\hline Item & Factor Loading \\
\hline 1 & 0.50 \\
\hline 2 & 0.69 \\
\hline 3 & 0.54 \\
\hline 4 & 0.17 \\
\hline 5 & 0.38 \\
\hline 6 & 0.57 \\
\hline 7 & 0.44 \\
\hline 8 & 0.61 \\
\hline 9 & 0.39 \\
\hline 10 & 0.40 \\
\hline
\end{tabular}

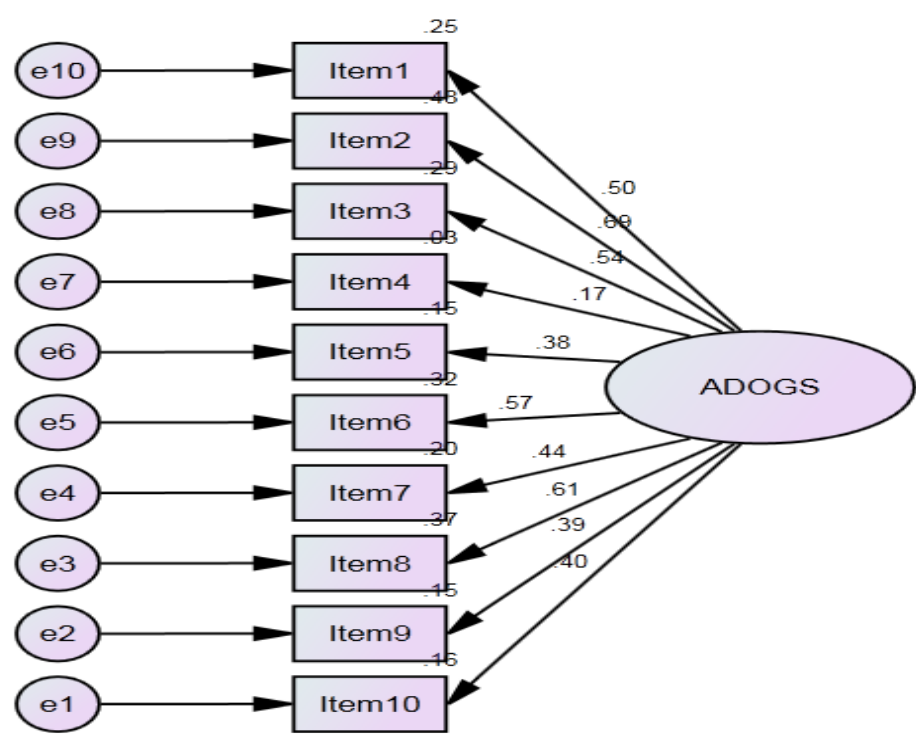

Fig: 1 Factor Loading of 10 Items on ADOG using SPSS Amos Ver. 23

The TLI value was 0.974 . The CFI value was 0.979 . The cut-off value of all the measures of goodness of fit is 0.93 . These evidences confirm the single-factor structure of academic delay of gratification as found in the first study by Bembenutty and Karabenick in American context. The use of Cronbach's alpha as the measure of reliability of a unidimensional construct is justified, without the violation of Tau-equivalence model as in this test, each of the 10 items measured the same latent trait, academic delay of gratification, on the same scale ADOGS (Green \& Thompson, 2005, Graham, 2005). The acceptable reliability value also confirms the measurement of single latent trait by the scale. It thus establishes the within-network construct validity of the variable's tool, table 2 .

For between-network validity, it is hypothesized that for the display of academic delay of gratification as a trait, the presence of emotional intelligence in the persona is called for.

(c) The International Journal of Indian Psychology, ISSN 2348-5396 (e)| ISSN: 2349-3429 (p) | 155 
Validation of Academic Delay of Gratification Scale among Indian Professional Courses Students

Table 2. Goodness of Fit Measures for Within - Network Construct Validity

\begin{tabular}{|c|c|c|c|c|c|c|c|c|}
\hline Measure & P value & CMIN/DF & RMR & RMSEA & GFI & IFI & TLI & CFI \\
\hline Benchmark & $>0.05$ & $<3$ & $<0.08$ & $<0.08$ & $>0.93$ & $>0.93$ & $>0.93$ & $>0.93$ \\
\hline Result & 0.319 & 1.097 & 0.069 & 0.028 & 0.944 & 0.981 & 0.974 & 0.979 \\
\hline
\end{tabular}

To quantify the claim, statistical technique of correlation was carried out on 136 students to express the nature and strength of the relationship between these variables in terms of correlation coefficient $r$ for level of significance 0.05 . SPSS ver.23 software provided a result of 0.511 , significant at 0.01 level of significance. It means that both the variables are related moderately in strength to each other, very significantly. The coefficient of determination $\mathrm{R}^{2}$ is 0.2611 , which means that emotional intelligence can bring in $26.11 \%$ of change in academic delay of gratification or vice-versa.

Table 3. Correlation between ADOG and EI for Between Network Construct Validity

\begin{tabular}{|c|c|c|c|c|c|c|}
\hline $\boldsymbol{\alpha}$ & Effect Size & Power & Req. Sample Size & Sample Size & $\mathbf{r}$ & $\mathbf{R}^{2}$ \\
\hline 0.05 & 0.3 & 0.9 & 112 & 136 & $0.511^{*}$ & 0.2611 \\
\hline
\end{tabular}

*Correlation in significant at 0.01 level

Taking the input of power analysis into consideration, like a moderate effect size of 0.3 , power 0.9 and level of significance 0.5 , one can safely say that there is enough evidence to reject the null hypothesis and accept the alternate hypothesis that there is a relationship between the emotional intelligence and academic delay of gratification in professional courses students which is of medium strength and effect in the population. This establishes between-network construct validity of the instrument, table 3 .

\section{DISCUSSION}

The Filipino version by Ganotice Jr, F. A., \& King, R. B. (2014)., the Japanese version by Nakanishi, M., Nakaya, M., \& Nakanishi, Y. (2015)., Iranian version by Arabzadeh, M., \& Kadivar, P. (2012), the Chinese version by King, .R. B., \& Du, .H. (2011) of AADOGS are available. The administration of the tool and obtaining of expected results from the tool happened in the case of Korean students (Bembenutty,. H., 2007) as well. The present study tried to validate the tool in Indian context.

The sample size was more than 1:20 ratio of subject to item. The reliability of the instrument was acceptable when administered on a sample of 336 subjects. Exploratory factor analysis extracted two factors when principal factor analysis extraction method along with varimax rotation was employed. However, parallel analysis finally revealed single factor dimensionality of the construct. To confirm the same, confirmatory factor analysis was carried out on another 125 subjects in the sample. Except item 4, all the items loaded significantly on the construct. A host of goodness of fit measures was selected to confirm the single factor structure and they provided

sufficient evidence for the same, under within-network construct validity approach. The

(C) The International Journal of Indian Psychology, ISSN 2348-5396 (e) | ISSN: 2349-3429 (p) | 156 
construct academic delay of gratification, as hypothesized, was found to be very significantly and in moderate strength be related to emotional intelligence. The result has medium effect size of 0.3 level of significance 0.05 and power of 0.9 under power analysis, providing evidence for between-network construct validity. Since the single dimension factor structure, acceptable Cronbach alpha reliability and construct validity are displayed by the instrument, it can be used in its present form on Indian urban adolescent college students to measure their academic delay of gratification trait.

However, further studies on validation of the tool must be carried out on students of academic courses at under graduation and post graduation levels in different states of a culturally diverse country like India. In such a scenario, the tool's version in the local language must be prepared by seeking the help of regional language experts involving cross-validation technique.

\section{Acknowledgments}

The author appreciates all those who participated in the study and helped to facilitate the research process.

Conflict of Interests: The author declared no conflict of interests.

\section{REFERENCES}

Arabzadeh, M., \& Kadivar, P. (2012): "Examination Of Reliability, Validity, And Factor Analysis Of Academic Delay Of Gratification Scale”, Training Measurement, Fall, Volume 3 , Number 9, pp. 1 - 17.

Barrett, P. (2007), "Structural Equation Modelling: Adjudging Model Fit," Personality and Individual Differences, 42 (5), 815-24.

Bembenutty,. H.(2007), "Self-Regulation of Learning and Academic Delay of Gratification among Korean College Students”, Online Submission, Paper presented at the Annual Meeting of the American Educational Research Association, Chicago, IL.

Bembenutty,.H., (2007), "Self-Regulation of Learning and Academic Delay of Gratification: Gender and Ethnic Differences Among College Students”, Journal of Advanced Academics, Vol.18, No.4, pp.586-616.

Bembenutty,. H., (2009), "Test anxiety (evaluation) and ADOG (Educational Aspects), ”College Student Journal, Project Innovation (Alabama) ISSN: 0146-3934.

Bembenutty,. H., Karabenick, S. A.,(1998),“Academic Delay of Gratification”, Learning and Individual Difference, Volume 10, Number 4, 1998, pages 329-346, ISSN: 1041-6080.

Bland, .J, Altman, .D. (1997), “Statistical Notes: Cronbach’s Alpha”, BMJ, 314:275.

Chakraborty, .R., (2016), “ A Narrative Review of the Literature on Academic Delay of Gratification Construct”, iJARS International Journal of Humanities and Social Studies, Volume II, Issue 4, ISSN: 2455-1465 (July/Aug-2016),

DOI: 10.20908/ijarsijhss.v2i4.11195. 
Chakraborty,.R., \& Prabhakaram, K.S. (2015), “A Study on the Relationship Between Delay of Gratification and Emotional Intelligence in Secondary School Students”, iJARS International Journal of Humanities and Social Studies, 1(1).

Costello, A.B, \& Osborne, J.W. (2005), "Best Practices in Exploratory Factor Analysis: Four Recommendations for Getting the Most from your Analysis", Practical Assessment, Research and Evaluation, 10(7).

DeVellis,.R., (2003), “Scale development: Theory and Applications”, Thousand Okas, CA: Sage.

Fabrigar, L. R., Wegener, D. T., MacCallum, R. C., \& Strahan, E.J. (1999), “Evaluating the use of exploratory factor analysis in psychological research”, Psychological methods, 4(3), 272-299.

Ganotice Jr, F. A., \& King, R. B. (2014)., "Blessed are those who wait: Validating the Filipino version of the Academic Delay of Gratification Scale (ADOGS)", The Asia-Pacific Education Researcher, 23(1), 19-27.

Gerbing, D. W., \& Anderson, J. C. (1985),” The effects of sampling error and model characteristics on parameter estimation for maximum likelihood confirmatory factor analysis”, Multivariate Behavioral Research, 20, 255-271.

Graham J. ,(2006), “Congeneric and (Essentially) Tau-Equivalent estimates of score reliability: what they are and how to use them", Educational Psychological Measurement, 2006;66:930-44.

Green S, Thompson M.(2005)," Structural equation modeling in clinical psychology research", In: Roberts M, Ilardi S, editors. Handbook of research in clinical psychology. Oxford: Wiley-Blackwell.

Hayduk, L., Cummings, G.G., Boadu, K., Pazderka-Robinson, H., and Boulianne, S. (2007), "Testing! Testing! One, Two Three - Testing the theory in structural equation models!," Personality and Individual Differences, 42 (2), 841-50.

Iacobucci,D. (2010), "Structural Equations Modeling: Fit Indices, sample size, and advanced topics”, Journal of Consumer Psychology 20, pp. 90-98.

King, .R. B., \& Du, .H. (2011), "All Good Things Come to Those Who Wait: Validating the Chinese Version of the Academic Delay of Gratification Scale (ADOGS)" The International Journal of Educational and Psychological Assessment Vol. 7 Iss. 1.

Kline, R.B. (2004), "Principles and Practice of Structural Equation Modelling" (2nd Edition ed.). New York: The Guilford Press.

Leach, C. W., van Zomeren, M., Zebel, S., Vliek, M. L. W., Pennekamp, S. F., Doosje, B., Ouwerkerk, J. W., \& Spears, R. (2008), "Group-level self-definition and self-investment: A hierarchical (multicomponent) model of in-group identification”, Journal of Personality and Social Psychology, 95(1), 144-165.

Markus, H. R. \& Kitayama,S.(1991), "Culture and Self: Implications for cognition, emotion and motivation”, Psychological Review, 98, 224-253. 
Marsh, H.W.(1997), "The measurement of physical well-concept: A construct validation approach”, In. K. Fox (Ed.), The physical self concept: From motivation to well-being (pp 27-58), Champaign, IL: Human Kinetics.

Nakanishi, M., Nakaya, M., \& Nakanishi, Y. (2015)., "Development of the Japanese Version of the Academic Delay of Gratification Scale for Undergraduate Students”, Japanese Journal of Personality, 23(3),pp.197-200.

Nunnally J, Bernstein L.(1994), "Psychometric theory”, New York: McGraw-Hill Higher, INC; 1994.

Petrides, K. V., Sangareau, Y., Furnham, A., \& Frederickson, N. (2006), "Trait emotional intelligence and children's peer relations at school. Social Development”, 15, 537-547.

Ronnel B King and Hongfei Du (2011), "All Good Things Come to Those Who Wait: Validating the Chinese Version of the Academic Delay of Gratification Scale (ADOGS)" The International Journal of Educational and Psychological Assessment, 7 (1).

Streiner D.,(2003), "Starting at the beginning: an introduction to coefficient alpha and internal consistency", Journal of personality assessment. 2003;80:99-103.

Tabachnick, B.G., \& Fidell, L.S. (2001), “Using Multivariate Statistics”, Boston: Allyn and Bacon.

Velicer, W.F.,\& Jackson, D.N.(1990), “Component Analysis Versus Common Factor Analysis Some Future Observations”, Multivariate Behavioral Research, 25(1), 97-114.

Zhang,.L., Karabenick, S. A., \& Lauermann, F. (2011), “Academic delay of gratification and children"s study time allocation as a function of proximity to consequential academic goals”,. Learning and Instruction, 21(1), 77-94.

How to cite this article: Chakraborty R (2017), Validation of Academic Delay of Gratification Scale among Indian Professional Courses Students, International Journal of Indian Psychology, Volume 4, Issue 2, No. 92, ISSN:2348-5396 (e), ISSN:2349-3429 (p), DIP:18.01.117/20170402, ISBN:978-1-365-78192-6 